Short Note

\title{
Larvicidal effect of latex from Calotropis gigantea (L.) W.T. Aiton against the mosquito, Culex quinquefasciatus Say (Diptera: Culicidae)
}

Khondkar Ehteshamul Kabir ${ }^{1}$, Ataur Rahman Khan ${ }^{2}$ and A.S.M. Shafiqur Rahman ${ }^{* 2}$

${ }^{1}$ Laboratory of Integrated Pest Management, Institute of Biological Sciences, University of Rajshahi;

${ }^{2}$ Department of Zoology, University of Rajshahi; Rajshahi-6205, Bangladesh

Key words: Culex quinquefasciatus, Calotropis gigantea, latex, larvicidal effect.

*Corresponding author

The milkweed, Calotropis gigantea (L.) W.T. Aiton (Gentianales: Asclepiadaceae) locally known as Akond, is an evergreen, perennial shrub, and is widely distributed in sub-tropical and tropical countries. It has been reported that latices of the milkweeds including $C$. gigantea contain cardiac glycosides that vary in amount and type between species, between various plant parts of the same species and through time, and other noxious chemical substances including pyrrolizidinic alkaloids (Farrell et al., 1991).

The pant latex functions as defense chemicals against insect herbivores (Konno et al., 2006). Evidence of a defensive function of cardiac glycosides in comes largely from studies of milkweed insects that sequester host plant cardenoloides and are thus protected from predators. The alkaloids reported to be present in the latex of $C$. procera have been shown to contain insecticidal properties (Larhsini et al., 1997). Study of Ramos et al. (2006) showed that the $C$. procera latex contains the larvicidal compounds, which caused significant mortality in third stage larvae of Aedes aegypti. Public concern over the toxicity and environmental impact of synthetic pesticides has initiated the exploration and utilization of bioactive constituents derived from plants to control insect pests and vectors carrying harmful pathogens to plants and animals. Furthermore, pesticides derived from natural products are less toxic to the environment and biodegradable in nature (Isman, 2006). The aim of this study was to investigate the effect of latex of $C$. gigantea against the larvae of the mosquito, C. quinquefasciatus Say, which is the primary vector of the filarial worm, Wuchereria bancrofti, causing lymphatic filariasis and of many different arboviruses such as WNV both in the old and new world.
Test material: Milky latex of $C$. gigantea, grown in the campus of Rajshahi University, Bangladesh, was collected in early-March of 2000 with punching of the young stems using sharp pins. Before making the various concentrations of latex in ppm, the collected latex was poured into preweighed conical flask and weighed to obtain the wet weight of the latex. Then the latex was dried in the same flask for $24 \mathrm{~h}$ at $60^{\circ} \mathrm{C}$, and the flasks were weighed again to obtain the dry weight of the latex. The stock solution of the semisolid latex in $\mathrm{MeOH}(\mathrm{w} / \mathrm{v})$ was then appropriately added to the test water medium to obtain the desired concentrations for the assay.

Experimental insect: All experiments and mosquito larvae, C. quinquefasciatus Say were reared in the laboratory of the Institute of Biological Sciences, University of Rajshahi, Bangladesh at ca. $27 \pm 1^{\circ} \mathrm{C}, 40-60 \%$ relative humidity) and a 12:12h Light: Dark (L:D) photoperiod. The larvae were fed on brewer's yeast (Red Star ${ }^{\circledR}$, Wisconsin, USA) at 10, 20, 40, and $80 \mathrm{mg} /$ beaker for the $1^{\text {st }}-, 2^{\text {nd }}-, 3^{\text {rd }}-$ and $4^{\text {th }}$ instars respectively. Rearing water was changed daily and at each time new food was added. Relative humidity is a crucial factor affecting the life pattern of mosquitoes, such as mating and oviposition.

Larval bioassay procedure: Bioassays with latex on mosquito larvae were performed using a standard protocol of World Health Organization (WHO, 1981). Twenty-five 1st-, 2nd-, 3rd- and 4th instar larvae were released into $100 \mathrm{ml}$ glass beakers, containing $50 \mathrm{ml}$ of tap water to which the required volume of the latex preparation was applied, using a glass capillary micro-pipette (WIRETROL ${ }^{\circledR} \mathrm{II}$, Drummond Scientific Company, PA, USA) to obtain the desired concentrations, viz. 1000, 2000, 4000, 8000 and 16000 ppm. 
Three replications were made for each concentration and two controls, one with $50 \mathrm{ml}$ of tap water alone and the other with $50 \mathrm{ml}$ of tap water containing brewer's yeast. Each replication used 25 larvae. Control insects were similarly raised.

Statistical analysis: The mortality data were corrected by Abbott's (1925) formula and subjected to Probit analysis according to Finney method to estimate the concentration killing 50 percent of the larvae tested $\left(\mathrm{LC}_{50}\right)$ and their 95 percent fiducial limits $\left(\mathrm{FL}_{95}\right)$. The data were further subjected to one-way ANOVA to test the significance between concentrations and time.

In the present study the latex of $C$. gigantea has been used as natural bio-larvicide instead of synthetic pesticides. The results of the effect of crude latex of $C$. gigantea on mosquito larvae at various concentrations with different exposure periods are presented in Table 1. A perusal of the data show that the latex produced significant mortality in the mosquito larvae at different instars compared to untreated controls and was moderately toxic at high concentrations. Our findings found positively correlated to those of earlier works that investigated the effect of plant latex on some species of mosquitoes. Giridhar et al. (1984) reported that C. procera latex affects mosquito larvae at high concentration. Most recently Mwine et al. (2010) reported that Euphorbia tirucalli latex can bring about total mortality of Anopheles species larvae at the highest dilution used of 1: 250 in 5 days. In our experiment the effect of latex on larvae was found age-and concentration-dependent. The mortalities obtained at high concentrations suggest that the activity of the bioactive compounds in the latex was inhibited by the influence of the microenvironment. Larvicide bioassay procedures normally correlate mortality to the concentration of material present in the medium. However, the actual dosage of test materials intended for ingestion by larvae, to serve as stomach poisons, may be affected by various confounding factors such as sedimentation, more or less selective ingestion by larvae and wide variations in the larval feeding rate. Further statistical analysis of the mortality data using one-way Anova detected the significant difference between concentrations and durations $(\mathrm{P}<0.01)$ (Table 2$)$. Similar results have been reported with the use of latex water of C. gigantea that showed 100 percent mortality in
Anopheles stephensi, Culex pipiens, and Aedes aegypti larvae at 50000ppm (Singh, 1996). Anopheles labranchiae larvae treated with the latex water filtrate from the same species produced significant mortality at low concentration (Markouk et al., 2000). The toxic effect of latex has also been reported in hoppers of the desert locust with the injection of latex from $C$. procera (Al-Robai, 1997) and in the cabbage looper, Trichoplusia ni, with the use of latex from Asclepias curassavica (Dussourd, 1993). The present study also noted that a number of $4^{\text {th }}$ instar larvae failed to ecdyse, and their outer integument colour turned to black. This suggests that milky latex may contain phyto-ecdysteroid like components, which may interfere the moulting of the mosquito larvae. Besides peculiar coiling, sluggish movements were noted in treated larvae that demonstrate the effect of the latex on the nervous and/or muscular system. This might also lead to subsequent mortality in the larvae. Curiously, first instar larvae of the monarch butterfly (Danaus plexippus L.), a milkweed specialist, likewise became immobilized upon encountering latex of Asclepias humistrata Walt., apparently due to cardiac glycosides (Zalucki \& Brower, 1992).

A number of insect species from unrelated taxa have developed adaptations to sequester pyrrolizidine alkaloids and cardenolides from their host plants and to utilize them as defense chemicals against their own predators (Nishida, 2002). The mechanism of toxic action of the bioactive compounds in latex, especially cardiac glycosides and other chemical constituents to mosquito larvae is not determined. Larval mortality may occur due to cardiac glycosides, which inhibit the action of membrane-bound enzyme $\mathrm{Na}^{+} / \mathrm{K}^{+}$-ATPase (Horisberger et al., 1991) and thus are toxic to most animals. The possible trade-off of mortality with high concentration caused by the latex requires further investigation with changing concentrations and using solvent extraction. However, the results are encouraging and suggest that the crude latex of $C$. gigantea could be useful as an alternative to synthetic larvicides to suppress the larval populations of the mosquito. This indigenous technology seems to be economically feasible for controlling mosquitoes in the rural regions of the South and South-East Asian countries where sophisticated and expensive methods are not available all the time. 
Table 1: Larvicidal effect of latex obtained from Calotropis gigantea against different larval instars of Culex quinquefasciatus. ${ }^{*}$

\begin{tabular}{cccccc}
\hline $\begin{array}{c}\text { Larval } \\
\text { instar }\end{array}$ & $\begin{array}{c}\text { Duration of } \\
\text { treatment (hrs) }\end{array}$ & $\begin{array}{c}\text { No. of larvae } \\
\text { used }\end{array}$ & $\begin{array}{c}\mathrm{LC}_{50} \text { values } \\
(\mathrm{ppm})\end{array}$ & Regression equation & $\begin{array}{c}\text { 95\% fiducial limits } \\
\text { Lower Upper }\end{array}$ \\
\hline 1st & 12 & 75 & 7575.47 & $\mathrm{Y}=1.29+0.95 \mathrm{X}$ & $5233.68-10965.09$ \\
& 24 & & 4305.88 & $\mathrm{Y}=1.74+0.89 \mathrm{X}$ & $3078.33-6022.94$ \\
2nd & 12 & 75 & 12166.47 & $\mathrm{Y}=0.96+0.98 \mathrm{X}$ & $7731.42-19145.61$ \\
& 24 & & 8692.60 & $\mathrm{Y}=0.72+1.08 \mathrm{X}$ & $6131.73-12323.02$ \\
3rd & 12 & 75 & 9374.22 & $\mathrm{Y}=0.69+1.08 \mathrm{X}$ & $6527.17-13463.12$ \\
& 24 & & 8672.16 & $\mathrm{Y}=0.60+1.11 \mathrm{X}$ & $6177.57-12174.12$ \\
4th & 12 & 75 & 15062.6 & $\mathrm{Y}=0.20+1.14 \mathrm{X}$ & $9661.24-23483.7$ \\
& 24 & & 11978.41 & $\mathrm{Y}=8.01+1.20 \mathrm{X}$ & $8261.99-17366.54$ \\
\hline
\end{tabular}

*Values were based on four concentrations, and three replications with 25 insects each

Table 2: Single factorial ANOVA for the mortality of 1st-, 2nd-, 3rd- and 4th instar larvae of Culex quinquefasciatus treated with the latex from C. gigantea.

\begin{tabular}{|c|c|c|c|c|c|}
\hline \multirow{2}{*}{\multicolumn{2}{|c|}{ Sources of variation }} & SS & DF & MS & F-value \\
\hline & & 1266.60 & 4 & 316.65 & $191.9^{* \star \star}$ \\
\hline & *b) & 1398.40 & 4 & 349.60 & $76.00^{\star \star \star}$ \\
\hline & $\left.{ }^{*} \mathrm{C}\right)$ & 1640.00 & 4 & 410.00 & $820.00^{\star \star \star}$ \\
\hline & ${ }^{*} \mathrm{~d}$ ) & 1457.00 & 4 & 364.25 & $316.74^{\star \star \star}$ \\
\hline \multirow[t]{4}{*}{ Duration } & a) & 108.90 & 1 & 108.90 & $66.00^{\star \star \star}$ \\
\hline & b) & 19.60 & 1 & 19.60 & $4.26 \mathrm{~ns}$ \\
\hline & c) & 2.50 & 1 & 2.50 & $5.00 \mathrm{~ns}$ \\
\hline & d) & 14.40 & 1 & 14.40 & $12.52^{\star \star}$ \\
\hline \multirow[t]{4}{*}{ Error } & a) & 6.60 & 4 & 1.65 & \\
\hline & b) & 18.40 & 4 & 4.60 & \\
\hline & c) & 2.00 & 4 & 0.50 & \\
\hline & d) & 4.60 & 4 & 1.15 & \\
\hline \multirow[t]{4}{*}{ Total } & a) & 1382.10 & 9 & & \\
\hline & b) & 1436.40 & 9 & & \\
\hline & c) & 1644.50 & 9 & & \\
\hline & d) & 1476.00 & 9 & & \\
\hline
\end{tabular}

\section{Acknowledgements}

The first author (KEK) would like to extend his gratitude to the Director, Institute of Biological Sciences, University of Rajshahi, Bangladesh, for providing laboratory facilities and fellowship, and to the Ministry of Science and Technology, Government of the People's Republic of Bangladesh, for providing National Science and Technology Fellowship.

\section{References}

Abbott, W.S. 1925. A method of computing the effectiveness of an insecticide. J. Econ. Entomol. 8:265-267.

Al-Robai, A.A. 1997. Toxicological studies on the latex of the uscher plant Calotropis procera Ait in Saudi Arabia. IV. Effects of partly purified uscher latex and of the poison gland secretion of the uscherhopper; Poekilocerus bufonius Klug on the desert locust, Schistocerca gregaria Forskal (Orthoptera: Acrididae). Arab Gulf J. Sci. Res. 15:709-716.
Dussourd, D. E. 1993. Foraging with finesse: caterpillar adaptations for circumventing plant defenses. In: Caterpillars: ecological and evolutionary constraints on foraging (Stamp, N. E. and Casey, T., eds.), Chapman and Hall, New York, pp. 92131.

Farrell, B., Dussourd, D.E. \& Mitter, C. 1991. Escalation of plant defense: do latex/resin canals spur plant diversification? Am. Nat. 138:891-900.

Gatehouse, J.A. 2002. Plant resistance towards insect herbivores: a dynamic interaction. New Phytol.156:145-169.

Giridhar, G., Deval, K., Mittal, P.K. \& Vasudevan, P. 1984. Mosquito control by Calotropis procera latex. Pesticides, 18:26-29.

Horisberger, J.D., Lemas, V., Kraehenbuhl, J.P. \& Rossier, B.C. 1991. Structure-function relationship of Na, K-ATPase. Annu. Rev. Physiol. 53:565-584. 
Isman, M. B. 2006. Botanical insecticides, deterrents, and repellents in modern agriculture and an increasingly regulated world. Annu. Rev. Entomol. 51:45-66.

Konno, K., Ono, H., Nakamura, M., Tateishi, K., Hirayama, C., Tamura, Y., Hattori, M., Koyama, A., \& Kohno, K. 2006. Mulberry latex rich in antidiabetic sugar-mimic alkaloids forces dieting on caterpillars. Proc. Natl. Acad. Sci. U S A., 103:1337-1341.

Larhsini, M., Bousad, M., Lazrek, H.B., Jana, M. \& Amarouch, H. 1997. Evaluation of antifungal and molluscicidal properties of extracts of Calotropis procera. Fitoterapia 68:371-373.

Markouk, M., Bekkouche, K., Larhsini, M., Bousaid, M., Lazrek, H. B. \& Jana, M. 2000. Evaluation of some Moroccan medicinal plant extracts for larvicidal activity. J. Ethnopharmacol. 73:293- 297.

Mwine, J., Van Damme, P. \& Jumba, F. 2010. Evaluation of larvicidal properties of the latex of Euphorbia tirucalli L. (Euphorbiaceae) against larvae of Anopheles mosquitoes. J. Med. Plants Res. 4:1954-1959.

Nishida, R. 2002. Sequestration of defensive substances from plants by Lepidoptera. Ann. Rev. Entomol. 47:57-92.

Ramos, M.V., Bandeira, G.P., de Freitas, C.D.T., Nogueira, N.A.P., Alencar, N.M.N., de Sousa, P.A.S. \& Carvalho, A.F.U. 2006. Latex constituents from Calotropis procera (R. Br.) display toxicity upon egg hatching and larvae of Aedes aegypti (Linn). Mem. Instit. Oswaldo Cruz. 101:503-510.
Seiber, J.N., Nelson, C.J. \& Lee, S.M. 1982 Cardenolides in the latex and leaves of seven Asclepias species and Calotropis procera. Phytochemistry, 21:2343-2348.

Singh, R. P. 1996 Monograph on promising pest control plant species of Asia and the pacific. Food and Agricultural Organization of the United Nations Regional Office for Asia and the Pacific (RAP), Bangkok, Thailand, pp. 37-38.

WHO,1981. Instructions for determining the susceptibility or resistance of mosquito larvae to insecticides. Document WHO/VBC/81, 807, World Health Organization, Geneva.

Zalucki, M.P. \& Brower, L.P. 1992. Survival of first instar larvae of Danaus plexippus (Lepidoptera: Danainae) in relation to cardiac glycoside and latex content of Asclepias humistrata (Asclepiadaceae). Chemoecol. 3:81-93. 